Arq. Bras. Med. Vet. Zootec., v.63, n.1, p.158-164, 2011

\title{
Avaliação genética para peso corporal em um rebanho Nelore
}

\author{
[Genetic evaluation for body weight in a Nellore herd] \\ F.M. Gonçalves, A.V. Pires*, I.G. Pereira, D.A. Garcia, M.M. Farah, C.T. Meira, V.A.R. Cruz \\ Departamento de Zootecnia - UFVJM \\ Rod. BR 386, km 583, n 5000 \\ 39100-000 - Diamantina, MG
}

\begin{abstract}
RESUMO
Estimaram-se as herdabilidades para os efeitos genéticos direto e materno e as correlações genéticas entre essas variáveis para os pesos ao desmame (P205), ao ano (P365) e ao sobreano (P550) em um rebanho Nelore do norte de Minas Gerais. O modelo estatístico incluiu os efeitos aditivos direto e materno, os efeitos fixos de grupo de contemporâneos (fazenda, sexo, regime alimentar, estação (seca e água) e ano de nascimento do animal) e o efeito da covariável idade da vaca ao parto (linear e quadrático). Os componentes de variância e os valores genéticos foram estimados utilizando-se o método REML. A tendência genética foi obtida utilizando-se a regressão do valor genético médio anual em relação ao ano de nascimento dos animais. As estimativas de herdabilidade do efeito aditivo direto $\left(\mathrm{h}_{\mathrm{D}}^{2}\right)$ para P205, P365 e P550 foram 0,60, 0,69 e 0,75, respectivamente. Estes coeficientes de $h_{0}^{2}$ são de alta magnitude, indicando que o rebanho apresenta variabilidade genética aditiva relativa e, portanto, espera-se progresso genético considerável utilizando a seleção. Pela análise da tendência genética, verificou-se que houve evolução nos valores genéticos dos animais ao longo dos anos estudados.
\end{abstract}

Palavras-chave: bovino de corte, tendência genética, herdabilidade, REML

\begin{abstract}
The heritabilities for direct and maternal genetic effects and genetic correlations between these effects were estimated for weight at 205 (P205), 365 (P365), and 550 days (P550) in a Nelore herd in northern Minas Gerais. The statistical model included direct and maternal additive effects, in addition to the fixed effects of contemporary group (farm, gender, diet, season - dry and water -, and year of birth) and the covariate age of cow at calving (linear and quadratic effects). The variance components and genetic values were estimated by REML method. The genetic trend was obtained using the regression of the annual mean genetic value in relation to the year birth. The heritability estimates for the direct additive effect $\left(\mathrm{h}_{\mathrm{D}}^{2}\right)$ for P205, P365, and P550 were equal to 0.60, 0.69, and 0.75, respectively. These coefficients showed high magnitude, indicating that the herd in question presents a great additive genetic variability and therefore it is expected a great progress using genetic selection. By the analysis of genetic trend, it was verified a development in animals genetic values over the years studied.
\end{abstract}

Keywords: genetic trend, heritability, beef cattle, REML

\section{INTRODUÇÃO}

Em um programa de melhoramento genético animal, a seleção para maximizar a produção é uma das mais importantes decisões a ser tomada pelo pecuarista moderno. Um pré-requisito para

Recebido em 7 de julho de 2009

Aceito em 22 de dezembro de 2010

*Autor para correspondência (corresponding author)

E-mail: aldrin@ufvjm.edu.br o sucesso desses programas é a obtenção de estimativas acuradas de parâmetros genéticos. Destaca-se que as estimativas de parâmetros genéticos para características ponderais na raça Nelore têm apresentado grande variabilidade, sendo um bom indicador da resposta à seleção ou ao melhoramento genético a ser alcançado. 
Machado et al. (1999) encontraram herdabilidade para peso aos 205 dias de idade na ordem de 0,62, enquanto Sarmento et al. (2003) verificaram herdabilidade para ganho de peso diário em bovinos Nelore na ordem 0,12. Esses parâmetros são necessários para estimar as respostas diretas e correlacionadas à seleção, para elaborar índices de seleção e predizer o valor genético dos animais (Gunski et al., 2001).

Boligon et al. (2008), ao realizarem estudos sobre associações genéticas entre pesos e características reprodutivas em rebanhos da raça Nelore, relataram que a estimativa de herdabilidade para peso aos 365 dias de idade (P365) na raça Nelore foi de 0,30. Já Sarmento et al. (2003) encontraram herdabilidade para P365 de 0,42 e destacaram que o ganho genético por meio da seleção pode ser alcançado, principalmente em idades mais avançadas, ou seja, no período de pós-desmama. Resultados semelhantes foram relatados por Machado et al. (1999), ao estudarem parâmetros genéticos para características ponderais de bovinos Nelore, em que a herdabilidade estimada foi de 0,43.

O peso aos 550 dias de idade (P550) e ao ano (P365) são características que expressam a habilidade do animal em ganhar peso no período pós-desmama. Existe uma tendência de redução da idade do peso aos 550 dias, com a finalidade de intensificar o processo de seleção, procurando selecionar animais que atinjam pesos desejados com a maior precocidade produtiva possível (Lira et al., 2008). Ribeiro et al. (2001) estimaram herdabilidade para efeitos direto $\left(h_{D}^{2}\right)$ e materno $\left(h_{M}^{2}\right)$ para P550 em bovinos Nelore e encontraram $h_{D}^{2}=0,76$, e $h_{M}^{2}=0,01$, comprovando que nesta idade há menor influência da mãe sobre o fenótipo da cria. Os autores descreveram, ainda, que esse fato ocorre devido ao antagonismo entre os efeitos dos genes para potencial de crescimento e a habilidade materna.

De modo geral, percebe-se grande variação nos valores de herdabilidade para as características ponderais em bovinos Nelore reportadas na literatura científica, o que pode ser justificado pelas diferenças na homogeneidade do ambiente ao qual os animais foram submetidos, pelas diferenças genéticas entre os rebanhos e pelas diferenças nos modelos estatísticos utilizados pelos vários autores (Mascioli et al., 1996, citados por Machado et al., 1999).

Neste sentido, o presente trabalho teve o objetivo de estimar a herdabilidade e a tendência genética para os efeitos genéticos direto e materno e as correlações genéticas entre esses efeitos para os pesos ao desmame, ao ano e ao sobreano de um rebanho Nelore do norte de Minas Gerais.

\section{MATERIAL E MÉTODOS}

Os dados analisados são provenientes de um rebanho da raça Nelore, da Colonial Agropecuária, situada no município de Janaúba, norte de Minas Gerais. Os dados destes animais são monitorados pelo Programa de Melhoramento Genético da Raça Nelore (PMGRN). As características estudadas foram pesos ao desmame (P205), ao ano (P365) e ao sobreano (P550), padronizados para os 205, 365 e 550 dias de idade, respectivamente. Estes pesos são utilizados como critério de seleção dentro do PMGRN. De modo geral, os animais, manejados permanentemente em pastagens, receberam suplementação proteico-mineral na época da seca.

Para a realização deste trabalho, partiu-se de uma base de dados atualizada até o ano de 2006, com 23.631 animais na matriz de parentesco. Com o objetivo de estimar variâncias e covariâncias genéticas, utilizaram-se 7.419 dados de pesos para P205, 5.211 para P365 e 2.584 para P550, de animais nascidos entre os anos de 1980 e 2006.

As análises preliminares para consistência dos dados e formação dos grupos de contemporâneos foram realizadas por meio do software Statistical Analysis System (SAS, 2002). Os grupos de contemporâneos (GC) foram compostos por sexo, fazenda (cinco), regime alimentar (nove), estação (outubro a março = chuvosa, e março a setembro $=$ seca) $\mathrm{e}$ ano de nascimento dos animais (1980 a 2006). Na Tab. 1, é apresentada uma estatística descritiva dos dados avaliados.

Os componentes de variâncias genética, residual e fenotípica, utilizados para a obtenção das estimativas de herdabilidade e correlações, foram estimados pelo método da máxima verossimilhança restrita, utilizando-se o software MTDFREML (Boldman et al., 1995). Utilizou-se 


\section{Gonçalves et al.}

como critério de convergência a variância do simplex que foi igual a $10^{-9}$. Para conferir a convergência, repetiu-se a análise com os parâmetros estimados no processamento anterior até que não houvesse variação na quarta casa decimal do $\log -2 \lambda$, por duas re-inicializações consecutivas.

Tabela 1. Estatística descritiva para peso ao desmame (P205), peso ao ano (P365) e peso ao sobreano (P550) de um rebanho Nelore

\begin{tabular}{lcccc} 
Característica & $\begin{array}{c}\text { Número de } \\
\text { observações }\end{array}$ & $\begin{array}{c}\text { Número de grupos } \\
\text { contemporâneos }\end{array}$ & $\begin{array}{c}\text { Média } \\
(\mathrm{kg})\end{array}$ & $\begin{array}{c}\text { Desvio-padrão } \\
(\mathrm{kg})\end{array}$ \\
\hline P205 & 7419 & 135 & 185,79 & 30,66 \\
P365 & 5211 & 121 & 245,09 & 42,34 \\
P550 & 2584 & 73 & 322,20 & 58,65 \\
\hline
\end{tabular}

O modelo animal para característica única incluiu os efeitos fixos de GC, idade da mãe ao parto como covariável (linear e quadrática), e os efeitos aleatórios de animal (genético direto), mãe (genético materno), de ambiente permanente e ambiental (residual).

O modelo animal utilizado para a análise dos dados foi representado por:

$y=x \underline{b}+z_{1} d+z_{2} \underset{\sim}{m}+z_{3} p+e$, em que:

$y=$ vetor de observações;

$X=$ matriz de incidência de efeitos fixos;

$b=$ vetor de efeitos fixos;

$Z_{1}=$ matriz de incidência de efeitos genéticos aditivos diretos;

$$
\left[\begin{array}{c}
\mathrm{y} \\
\tilde{\mathrm{d}} \\
\tilde{\mathrm{m}} \\
\tilde{\sim} \\
\mathrm{p} \\
\tilde{\mathrm{e}} \\
\sim
\end{array}\right] \sim\left\{\left[\begin{array}{c}
\mathrm{X} \mathrm{b} \\
\tilde{\sim} \\
\tilde{\sim} \\
0 \\
\tilde{\sim} \\
\tilde{\sim} \\
\underset{\sim}{0}
\end{array}\right] ;\left[\begin{array}{ccccc}
\mathrm{V} & \mathrm{Z}_{1} \mathrm{D}+\mathrm{Z}_{2} \mathrm{C} & \mathrm{Z}_{2} \mathrm{M}+\mathrm{Z}_{1} \mathrm{C} & \mathrm{Z}_{3} \mathrm{P} & \mathrm{R} \\
\mathrm{DZ}_{1}^{\prime}+\mathrm{CZ}_{2}^{\prime} & \mathrm{D} & \mathrm{C} & \phi & \phi \\
\mathrm{MZ}_{2}^{\prime}+\mathrm{CZ}_{1}^{\prime} & \mathrm{C} & \mathrm{M} & \phi & \phi \\
\mathrm{PZ} & \phi & \phi & \mathrm{P} & \phi \\
\mathrm{R} & \phi & \phi & \phi & \mathrm{R}
\end{array}\right]\right\}
$$

em que $\mathrm{V}=\mathrm{Z}_{1} \mathrm{DZ}_{1}^{\prime}+\mathrm{Z}_{2} \mathrm{MZ}_{2}^{\prime}+\mathrm{Z}_{1} \mathrm{CZ}_{2}^{\prime}+\mathrm{Z}_{2} \mathrm{CZ}_{1}^{\prime}+\mathrm{Z}_{3} \mathrm{PZ}_{3}^{\prime}+\mathrm{R}$.

As matrizes D, M, C, P, R e $\phi$ são dadas por:

$\mathrm{D}=\mathrm{A} \times \sigma_{\mathrm{D}}^{2}$;

$\mathrm{M}=\mathrm{A} \times \sigma_{\mathrm{M}}^{2}$;

$\mathrm{C}=\mathrm{A} \times \sigma_{\mathrm{DM}} ;$

$\mathrm{P}=\mathrm{Ix} \sigma_{\mathrm{P}}^{2}$;

$\mathrm{R}=\mathrm{Ix} \sigma_{\mathrm{R}}^{2}$, em que:

$\sigma_{\mathrm{D}}^{2}$ e $\sigma_{\mathrm{M}}^{2}$ são as variâncias genéticas aditivas direta e materna, respectivamente; $\sigma_{D M}$ é a covariância genética entre os efeitos direto e materno; $\sigma_{\mathrm{P}}^{2}$ é a variância atribuída aos efeitos $d=$ vetor de efeitos genéticos aditivos diretos;

$Z_{2}=$ matriz de incidência de efeitos genéticos aditivos maternos;

$m=$ vetor de efeitos genéticos aditivos maternos;

$Z_{3}=$ matriz de incidência de efeitos aleatórios de ambiente permanente da mãe do animal;

$p=$ vetor de efeitos aleatórios de ambiente permanente da mãe (vaca) do animal; $\mathrm{e}=$ vetor de efeito residual.

Admitindo-se que $y$ tenha distribuição normal multivariada, têm-se: 


\section{RESULTADOS E DISCUSSÃO}

As estimativas dos componentes de variância e das herdabilidades estão apresentadas na Tab. 2. As estimativas de herdabilidade foram de magnitude média a alta e, de um modo geral, maiores que os valores descritos na literatura.
Estes valores indicam a grande participação da variação genética aditiva na transmissão das características, evidenciando o uso da seleção massal como uma maneira eficiente para aumentar o progresso genético dessas características no rebanho.

Tabela 2. Estimativas das variâncias genéticas aditivas direta $\left(\sigma_{D}^{2}\right)$ e materna $\left(\sigma_{M}^{2}\right)$, covariância direta $x$ materna $\left(\sigma_{\mathrm{DM}}\right)$, variância de ambiente permanente $\left(\sigma_{\mathrm{P}}^{2}\right)$, herdabilidade direta $\left(\mathrm{h}_{\mathrm{D}}^{2}\right)$, herdabilidade materna $\left(h_{M}^{2}\right)$ e correlação entre os efeitos aditivos direto e materno $\left(r_{D M}\right)$ para P205, P365 e P550

\begin{tabular}{cccccccc}
\hline Característica & $\sigma_{\mathrm{D}}^{2}$ & $\sigma_{\mathrm{M}}^{2}$ & $\sigma_{\mathrm{DM}}$ & $\sigma_{\mathrm{P}}^{2}$ & $\mathrm{~h}_{\mathrm{D}}^{2}$ & $\mathrm{~h}_{\mathrm{M}}^{2}$ & $\mathrm{r}_{\mathrm{DM}}$ \\
\hline P205 & 474,83 & 255,72 & $-260,69$ & 0,91 & 0,60 & 0,32 & $-0,75$ \\
P365 & 936,89 & 244,43 & $-416,39$ & 58,51 & 0,68 & 0,18 & $-0,87$ \\
P550 & 1963,02 & 790,97 & $-1100,67$ & 0,15 & 0,75 & 0,30 & $-0,88$ \\
\hline
\end{tabular}

A estimativa da $\mathrm{h}^{2}$ do efeito genético aditivo direto para P205 foi de 0,60, valor mais alto que os observados por Martins et al. (2000), Ribeiro et al. (2001), Pereira et al. (2001), Sarmento et al. (2003), Bertazzo et al. (2004), Silveira et al. (2004) e Boligon et al. (2008), que obtiveram valores iguais a $0,42,0,16,0,22,0,12,0,25,0,17$ e 0,26, respectivamente. Porém, Machado et al. (1999) encontraram $h^{2}$ de 0,62 , valor mais alto que o estimado neste trabalho. A estimativa da $h^{2}$ do efeito materno para P205 foi de 0,32, considerada de magnitude mediana, indicando que nesta fase há influência da mãe em relação ao bezerro, fato que justifica a inclusão do efeito materno no modelo para se obter maior precisão na estimativa dos parâmetros genéticos.

A estimativa da $h^{2}$ do efeito genético aditivo direto estimada para P365 foi de 0,68, considerada de alta magnitude. Este valor é mais alto que os relatados por Machado et al. (1999), Ribeiro et al. (2001), Sarmento et al. (2003), Bertazzo et al. (2004) e Boligon et al. (2008), em que os valores encontrados foram $0,43,0,40$, 0,42, 0,24; e 0,30, respectivamente. Pimenta Filho et al. (2001) estimaram $h^{2}$ para P365 em rebanhos da raça Guzerá e também verificaram valor mais baixo, 0,26, ao estimado neste trabalho. Do mesmo modo, Ferraz Filho et al. (2002) estimaram $h^{2}$ para P365 de um rebanho raça Tabapuã e encontraram 0,17, sendo considerada de baixa magnitude pelo autor. A estimativa da $h^{2}$ do efeito materno para P365 obtida neste trabalho, foi de 0,18 , mais alta que as estimativas relatadas por Bertazzo et al. (2004) (0,03), Ferraz Filho et al. (2002) $(0,03)$ e
Boligon et al. (2008) (0,08), e mais baixa que a citada por Ribeiro et al. (2001) $(0,44)$. Os baixos valores de $\mathrm{h}^{2}$ materna relatados podem ser explicados pelo fato de o efeito materno ter menor contribuição nesta fase, pois este efeito tende a diminuir ao longo do tempo, sendo mínino aos 550 dias de idade.

O coeficiente de herdabilidade do efeito genético aditivo direto estimado para a característica P550 foi de 0,75, considerado alto, e mais elevado que os relatados por Garnero et al. (2001), Pereira et al. (2001), Siqueira et al. (2003), Silveira et al. (2004), Bertazzo et al. (2004) e Boligon et al. (2008), que encontraram valores de herdabilidade iguais a 0,34, 0,32, 0,47, 0,30, 0,35, e 0,30, respectivamente. Entretanto, o valor estimado neste trabalho foi semelhante aos observados por Machado et al. (1999) $(0,73)$ e por Ribeiro et al. (2001) $(0,76)$.

De modo geral, as herdabilidades para P205, P365 e P550 encontradas neste trabalho foram de alta magnitude, indicando que o rebanho em questão apresenta grande variabilidade genética relativa que pode ser explorada por seleção massal. Uma seleção intensa pode resultar em melhoras no desempenho médio da população e, consequentemente, promover progresso genético nas características de crescimento ao longo dos anos.

Na Fig. 1, encontram-se as tendências genéticas do efeito aditivo direto para as características analisadas. 

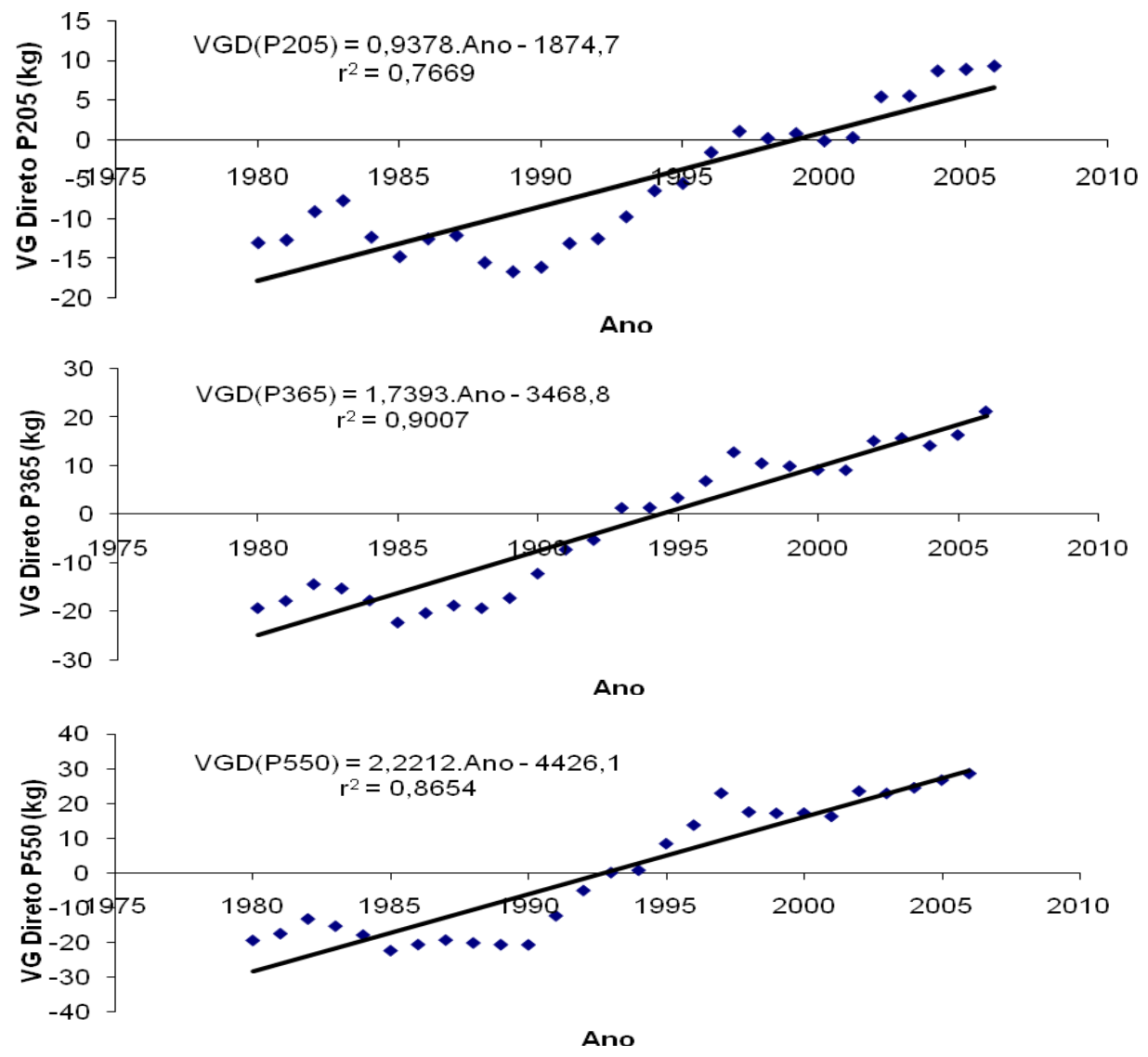

Figura 1. Tendência genética dos valores genéticos (VG) diretos para as características peso ao desmame (P205), ao ano (P365) e ao sobreano (P550) de bovinos Nelore, no período de 1980 a 2006.

A análise da tendência para os efeitos genéticos aditivos diretos apresentou-se crescente para as características P205 (0,9378kg/ano), P365 (1,7393kg/ano) e P550 (2,2212kg/ano), indicando que a seleção para peso nas idades analisadas está sendo eficiente para melhorar geneticamente o rebanho em questão. Essa tendência genética representa uma diferença de cerca de 25,32kg para P205, 46,96kg para P365 e $59,97 \mathrm{~kg}$ para P550 como consequência do progresso genético oriundo do efeito genético direto ao longo dos 27 anos estudados. Por estes resultados, percebe-se a eficácia do programa de melhoramento adotado neste rebanho, o qual propiciou uma positiva e acentuada alteração nos valores genéticos médios dos animais ao longo dos anos.

Na Fig. 2, estão apresentadas as tendências genéticas do efeito genético materno para as características estudadas. A análise de tendência genética materna foi decrescente para as características P205, -0,5kg/ano, P365, 0,722kg/ano e P550, -1,130kg/ano, fato esperado, uma vez que neste rebanho foi dada ênfase (seleção) para as características de produção (desempenho ponderal etc.), e a correlação entre os efeitos aditivos diretos e maternos apresentaram-se negativas, indicando antagonismo entre os genes que atuam para produção e aqueles que atuam para reprodução (efeito materno).

As estimativas de parâmetros genéticos e as tendências genéticas obtidas neste estudo estão acima da maioria dos valores descritos na literatura. Cabe ressaltar que os resultados obtidos referentes ao rebanho estudado são muito influenciados pela composição genética e pelas condições ambientais a que os animais foram submetidos, merecendo, portanto, cautela à aplicação prática desses resultados para uso generalizado. 

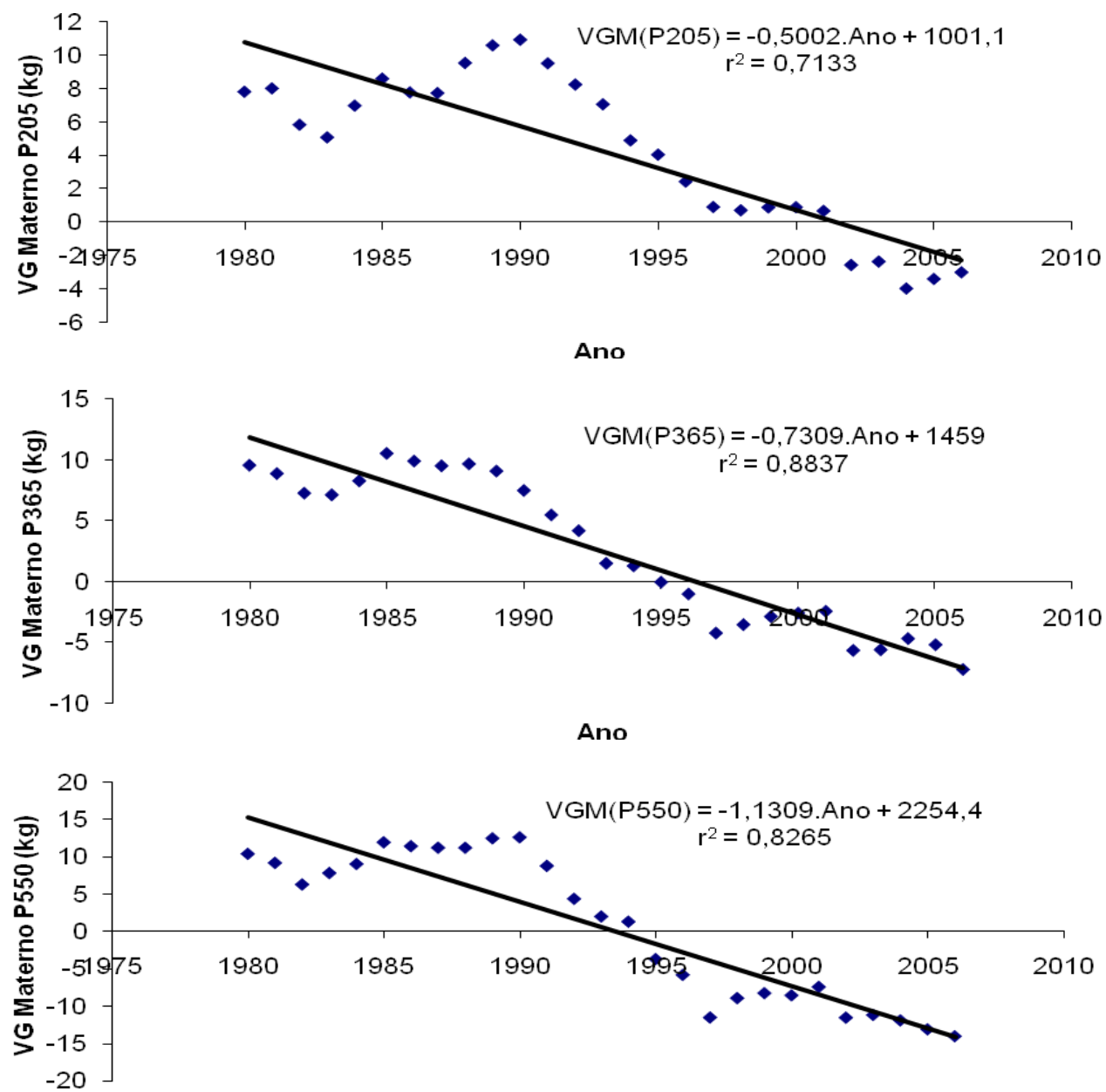

Ano

Figura 2. Tendência genética dos valores genéticos (VG) maternos para as características peso ao desmame (P205), ao ano (P365) e ao sobreano (P550) de bovinos Nelore no período de 1980 a 2006.

\section{CONCLUSÕES}

As estimativas de $h^{2}$ para o efeito genético direto obtidas para as características estudadas apresentaram-se com valores de magnitude alta, indicando que este rebanho apresenta grande potencial de resposta à seleção individual. As estimativas de $\mathrm{h}^{2}$ para o efeito materno foram moderadas, evidenciando a importância desse efeito e o fato de que ele deve ser incluído nos modelos para avaliação genética das características P205, P365 e P550, com o objetivo de estimar parâmetros genéticos com maior precisão. As correlações genéticas entre os efeitos genéticos aditivos direto e materno foram negativas e de média a alta magnitude, indicando forte antagonismo entre os efeitos dos genes para potencial de crescimento da cria e habilidade materna. As tendências genéticas dos valores genéticos diretos para as características estudadas apresentaram-se elevadas e crescentes, demonstrando que este rebanho obteve ganhos genéticos expressivos ao longo dos 27 anos estudados.

\section{REFERÊNCIAS BIBLIOGRÁFICAS}

BERTAZZO, R.P.; FREITAS, R.T.F.; GONÇALVES, T.M. et al. Parâmetros genéticos de longevidade e produtividade de fêmeas da raça Nelore. Rev. Bras. Zootec., v.33, p.11181127, 2004. 


\section{Gonçalves et al.}

BOLDMAN, K.G.; KRIESE, L.A.; Van VLECK, L.D. et al. A manual for use for MTDFREML. A set of programs to obtain estimates of variance and covariance [DRAFT]. Lincoln: Department of Agriculture/ Agricultural Research Service, 1995. 120p.

BOLIGON, A.A.; ALBUQUERQUE, L.G.; RORATO, P.R.N. Associações genéticas entre pesos e características reprodutivas em rebanhos da raça Nelore. Rev. Bras. Zootec., v.37, p.596601, 2008.

FERRAZ FILHO, P.B.; RAMOS, A.A.; SILVA, L.O.C. et al. Tendência genética dos efeitos diretos e maternos sobre os pesos à desmama e pós-desmama de bovinos da raça Tabapuã no Brasil. Rev. Bras. Zootec., v.31, p.635-640, 2002.

GARNEIRO, A.D.V.; LÔBO, R.B.; BEZERRA, L.A.F. et al. Comparação entre alguns critérios de seleção para crescimento na raça Nelore. Rev. Bras. Zootec., v.30, p.714-718, 2001.

GUNSKI, R.J.; GARNERO, A.D.V.; BORJAS, A.L.R. et al. Estimativas de parâmetros genéticos para características incluídas em critérios de seleção em gado Nelore. Cienc. Rural, v.31, p.603-607, 2001.

LIRA, T.; ROSA, E.M.; GARNEIRO, A.D.V. Parâmetros genéticos de características produtivas e reprodutivas em zebuínos de corte (revisão). Cienc. Anim. Bras., v.9, p.1-22, 2008.

MACHADO, P.F.A.; AQUINO, L.H.; GONÇALVES, T.M. Estimativas de parâmetros genéticos e critérios de seleção em características ponderais de bovinos Nelore. Cienc. Agrotecnol., v.23, p.197-204, 1999.

MARTINS, G.A.; FILHO, R.M.; LIMA, F.A.M. et al. Influência de fatores genéticos e de meio sobre o crescimento de bovinos da raça Nelore no estado do Maranhão. Rev. Bras. Zootec., v.29, p.103-107, 2000.
PEREIRA, E.; ELER, J.P.; FERRAZ, J.B.S. Análise genética de algumas características reprodutivas e suas relações com o desempenho ponderal da raça Nelore. Arq. Bras. Med. Vet. Zootec., v.53, p.720-727, 2001.

PIMENTA FILHO, C.E.; MARTINS, G.A.; SARMENTO, J.L.R. et al. Estimativas de herdabilidade de efeito direto e materno de características de crescimento de bovinos Guzerá, no estado da Paraíba. Rev. Bras. Zootec., v.30, p.1220-1223, 2001.

RIBEIRO, M.N.; PIMENTA FILHO, E.C.; MARTINS, G.A. et al. Herdabilidade para efeito direto e materno de características de crescimento de bovinos Nelore no estado da Paraíba. Rev. Bras. Zootec., v.30, p.1224-1227, 2001.

SARMENTO, J.L.R; PIMENTA FILHO, E.C.; RIBEIRO, M.N. et al. ; FILHO, R. M. Efeitos ambientais e genéticos sobre o ganho em peso diário de bovinos Nelore no estado da Paraíba. Rev. Bras. Zootec., v.32, p.325-330, 2003.

SILVEIRA, J.C.; McMANUS, C.; MASCIOLI, A.S. et al. Fatores ambientais e parâmetros genéticos para características produtivas e reprodutivas em um rebanho Nelore no estado do Mato Grosso do Sul. Rev. Bras. Zootec., v.33, p.1432-1444, 2004.

SIQUEIRA, R.L.P.G.; OLIVEIRA, J.A.; LÔBO, R.B. et al. Análise da variabilidade genética aditiva de características de crescimento na raça Nelore. Rev. Bras. Zootec., v.32, p.99-105, 2003. 